BANCA D'ITALIA

E U R O S I S T E M A

Questioni di Economia e Finanza

(Occasional Papers)

Cyber attacks: preliminary evidence from the Bank of Italy's business surveys

by Claudia Biancotti 

13 BANCA D'ITALIA

E U R O S I S T E M A

\section{Questioni di Economia e Finanza}

(Occasional papers)

Cyber attacks: preliminary evidence from the Bank of Italy's business surveys

by Claudia Biancotti

Number 373 - February 2017 
The series Occasional Papers presents studies and documents on issues pertaining to the institutional tasks of the Bank of Italy and the Eurosystem. The Occasional Papers appear alongside the Working Papers series which are specifically aimed at providing original contributions to economic research.

The Occasional Papers include studies conducted within the Bank of Italy, sometimes in cooperation with the Eurosystem or other institutions. The views expressed in the studies are those of the authors and do not involve the responsibility of the institutions to which they belong.

The series is available online at www.bancaditalia.it.

ISSN $1972-6627$ (print)

ISSN 1972-6643 (online)

Printed by the Printing and Publishing Division of the Bank of Italy 


\title{
CYBER ATTACKS: PRELIMINARY EVIDENCE FROM THE BANK OF ITALY'S BUSINESS SURVEYS
}

\author{
by Claudia Biancotti*
}

\begin{abstract}
This paper presents preliminary evidence on cyber risk in the Italian private sector based on the Bank of Italy's annual surveys of Italian industrial and service firms. The information collected, albeit only covering the incidence of cyber attacks and some aspects of security governance, is the first of its kind for Italy. The results are striking: even though a mere 1.5 per cent of businesses do not deploy any cybersecurity measures, 30.3 per cent corresponding to 35.6 per cent of total employees - report at least some damage from a cyber attack between September 2015 and September 2016. Once data are corrected to account for unwillingness to report or inability to detect attacks on the part of some respondents, these figures climb to 45.2 and 56 per cent respectively, with large, high-tech and internationally exposed businesses faring worse than average. The economy-wide risk level is likely to be higher still; the financial sector, healthcare, education and social care are excluded from the sample, but they are known from other sources to be particularly appealing to attackers.
\end{abstract}

JEL Classification: F50, L60, L80, C83.

Keywords: cyber attacks, cybersecurity, cyber risk.

\section{Contents}

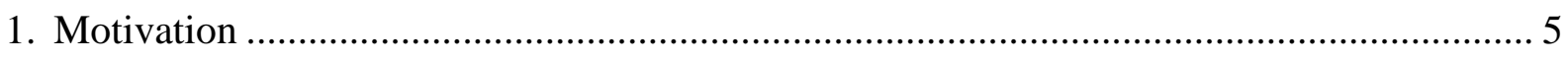

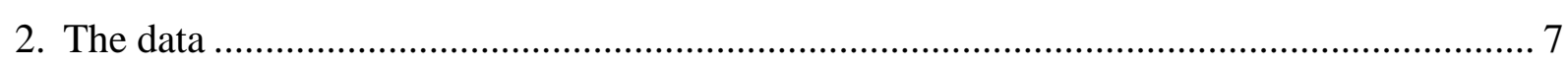

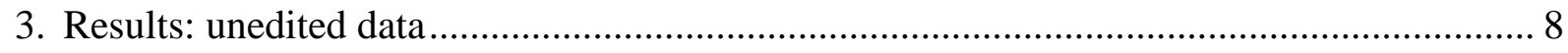

3.1 Cybersecurity management in Italian non-financial firms ........................................ 8

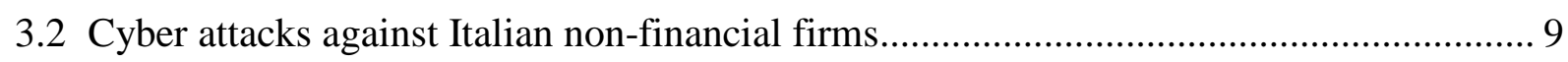

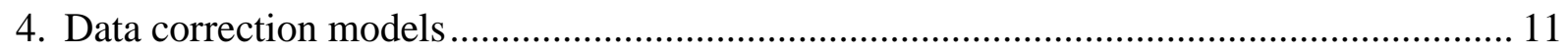

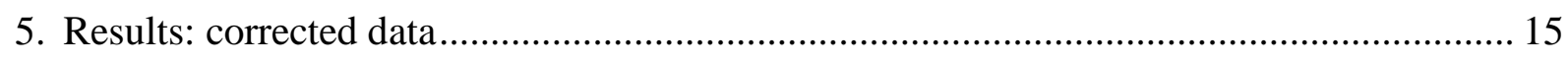

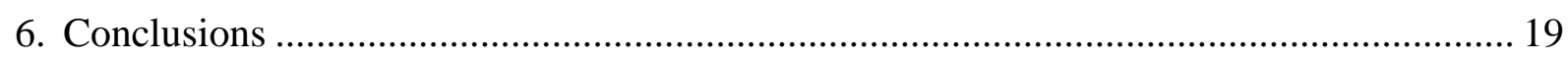

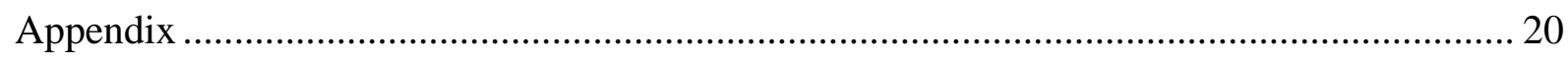

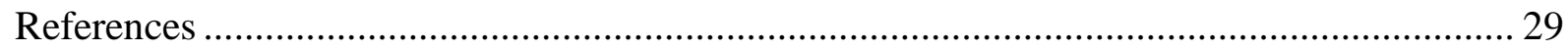

\footnotetext{
* Bank of Italy, Directorate General for Economics, Statistics and Research.
} 



\section{Motivation $^{1}$}

Cyber risk is currently at the top of the international agenda. Between 2012 and 2016, it featured three times in the World Economic Forum's list of significant global risks (World Economic Forum, various years). The concluding statement of the G7 Leaders' Summit of May 2016 reads: 'We strongly support an accessible, open, interoperable, reliable and secure cyberspace as one essential foundation for economic growth and prosperity' (G7 Leaders, 2016).

Some stakeholders have long been aware of the dangers of poor cybersecurity, ${ }^{2}$ however this concern has entered the mainstream only recently as lines between state-mandated cyber war, cyber terrorism, profitoriented cyber espionage and cybercrime blur (World Bank, 2016) and the broader implications of cyber attacks start to become clear.

Possible targets are no longer restricted to traditional strategic assets, such as military systems and largescale infrastructure, or to businesses that guarantee immediate monetary gain for the attacker upon a successful breach, such as providers of online payment services. ${ }^{3}$ Corporations that store massive amounts of personal data are now a prime object of desire for attackers: incursions that have made the front pages of newspapers - against medical insurer Anthem, e-mail provider Yahoo!, etc. - are only the tip of a growing iceberg of privacy breaches (Center for Strategic and International Studies, 2016), often perpetrated with goals that go beyond the sale of stolen data on black markets.

Disclosure of sensitive information is known to impact stock prices, at least in the short run (Spanos and Lefteris, 2016), can cause companies to fail and can affect political dynamics, as shown by the 2015 attacks on the Ukrainian power grid and the role played by hacked e-mail accounts in the 2016 US presidential campaign. Beyond such notable cases, any manufacturing or service firm can be targeted for theft of intellectual property or sabotage; any individual is at risk of financial fraud or identity theft.

Perhaps most importantly, the nature of cyberspace is such that anyone who owns a connected device can become an unwitting accomplice to a crime: a security flaw in a system can be leveraged to hit other systems. Attackers are likely to look for the weakest links in a company's supply chain: in 2013, US retailer

\footnotetext{
${ }^{1}$ I would like to thank Luigi Cannari, Pietro Catte, Paolo Ciocca, Riccardo Cristadoro, Pauline Massart and Giovanni Veronese for their comments. The Sample Surveys Division at the Bank of Italy and the cybersecurity community of the Italian government provided substantial help with the survey questions. All remaining mistakes and omissions are mine. The views here expressed are those of the author and should not be attributed to the Bank of Italy.

${ }^{2}$ The military and law enforcement implications of cyber vulnerabilities have been evident for some time and have been discussed multilaterally in forums as comprehensive as the United Nations (United Nations General Assembly, various years).

${ }^{3}$ International financial institutions were comparatively quick to react to the emergence of cyber risk. A few years ago the Bank for International Settlements and the International Organization of Securities Commissions, together with national and supranational supervisors, fostered a coordinated drive for enhanced security across banks and other financial institutions, ongoing today (Bank for International Settlements and Board of the International Organization of Securities Commissions, 2016). As an example of public-private partnership, in December 2016 the Bank of Italy and the Italian Banking Association created a Computer Emergency Response Team for the financial sector (CERTFin).
} 
Target was hit, causing total damage of about $\$ 300$ million via network credentials stolen from a lowsecurity, third-party provider of air-conditioning services. Poorly protected machines can also be hijacked: in 2016, about 100,000 Internet-of-Things ${ }^{4}$ (IoT) devices, such as digital video recorders and web cameras, were used, unbeknownst to the owners, to disrupt the operations of high-profile targets including social platforms Twitter and Reddit.

The damage caused by cyber attacks goes beyond individual victims: a widespread perception of excessive, inadequately managed risk could ultimately trigger a technological backlash (World Economic Forum, 2014). One of the clearest examples of vulnerability comes from knowledge-intensive services; in this sector, it is easy to see how a lack of cybersecurity could both stifle productivity and erode the gains from globalization. From cloud storage to e-commerce, from social networking to management consulting, many knowledge-intensive services are based on exchanges of digitized information; most have a crossborder dimension, with providers in one jurisdiction serving customers all over the world. Should consumers fear that their data are not safe, they might choose to exit the market, or at least withdraw from international trade. Indeed, pressure for repatriation of data has been mounting, based on the fear that information stored abroad is more exposed to both hackers and foreign governments. ${ }^{5}$ Security considerations can, and do, enter decisions on whether to develop and sell new information-based products, or where to establish dataintensive productive processes, such as industrial 3D printing. Cybersecurity regulations can constitute a barrier to trade as well (Friedman, 2013).

Recent academic literature shows how the market alone fails to provide adequate protection against cyber threats on account of distortive factors, such as asymmetric information, and the externalities exemplified above (Anderson, 1993; Anderson, 2001; Ashgari, van Eeten and Bauer, 2015; Moore, Dynes and Chang, 2016; van Eeten et al., 2010). Governments and researchers may be well acquainted with this fact in qualitative terms, however they often lack precise metrics. How vulnerable are businesses? How often are they attacked? What is the cost of security? A pressing need for reliable data emerges, since very little is

\footnotetext{
4 'Internet of Things' describes the growing network of physical objects, such as household appliances, cars or industrial machines, that are connected to the Internet so as to enable remote operation (e.g. control, maintenance, data transfer). Some users of IoT devices do not realize that they should protect them the way they would a computer or a smartphone; default configurations, including passwords, are often left untouched, resulting in widespread vulnerability. ${ }^{5}$ In 2015, based on the complaint of a Facebook customer, the European Court of Justice overturned the 'Safe Harbour' decision taken by the European Commission in 2000 (European Court of Justice, 2015). This decision allowed companies located in the United States to store data belonging to European citizens, as long as they selfcertified adherence to a set of privacy principles. After the decision was overturned, negotiations began for a new agreement, known as the US-EU Privacy Shield, which includes stronger safeguards and entered into force in 2016 (European Commission, 2016). While the Court's reasoning focused on the incompatibility between EU principles and US 'legislation permitting the public authorities to have access on a generalized basis to the content of electronic communications', the same concern applies even more so to the lack of a defence against any unauthorized access to data by attackers. Compliance with the Cyber Essentials scheme, a security certification programme run by the British government, is already a pre-requisite for bidding for certain public contracts in the United Kingdom; authorities are suggesting that private businesses adopt the same requirement (Crown Commercial Service of the United Kingdom Government, 2016). Federal procurement in the US has cybersecurity requirements (United States Department of Defense, General Service Administration, National Aeronautics and Space Administration, 2016); certification of compliance with the 2016 EU Directive on Security and Network Information Systems may come to play a similar role in Europe.
} 
known. The statistics most often quoted in the media are provided by companies that specialize in cyber defence: the potential for a conflict of interest exists and the underlying data are not public.

This paper presents a first-time overview of cyber risk in the Italian private sector based on the Bank of Italy's annual surveys of Italian industrial and service firms. This data source appears to be particularly suited to policy design as it draws on a random sample with known statistical properties, covers a significant share of the economy, documents the collection methodology, is available to researchers and comes from a provider with no commercial interest in cybersecurity. Similar characteristics can be found in the UK Government's Cyber Security Breaches Survey (United Kingdom Department for Culture, Media and Sport, 2016), already in its second wave at the time of writing.

The information collected, albeit only covering the incidence of cyber attacks and some aspects of security governance, is the first of its kind for Italy. The results are striking: even though a mere 1.5 per cent of businesses do not deploy any cybersecurity measure, 30.3 per cent - corresponding to 35.6 per cent of total employees - report at least some damage from a cyber attack between September 2015 and September 2016. Once data are corrected to account for inability to detect attacks on the part of some respondents, and reticence to disclose them on the part of others, these figures climb to 45.2 and 56 per cent respectively, with large, high-tech and internationally exposed businesses faring worse than average. The economy-wide risk level is likely to be higher still; the financial sector, healthcare, education and social care are excluded from the sample, but they are known from other sources to be particularly appealing to attackers.

The paper is structured as follows. Section 2 describes the data; Section 3 discusses the main findings using the unedited data; Section 4 illustrates the process of data correction; Section 5 reports results using the corrected data; Section 6 concludes. The Appendix provides further statistical details.

\section{The data}

Every year, the Bank of Italy carries out two surveys of the Italian private business sector covering industrial and non-financial service firms with at least 20 employees. The sample is randomly selected according to a stratified design; the results are statistically representative by macro-region, size class and certain aggregations of NACE Rev.2 sectors at the two-digit level (see Banca d'Italia, various years for methodological documentation).

Between January and May of each year, the main quantitative descriptors of a firm's economic activity (employment, investment, turnover) are measured. Between September and October, a qualitative follow-up records changes in those variables. ${ }^{6}$ Questionnaires also include time-varying monographic questions, driven by contingent informational needs. In 2016, the qualitative survey featured two questions on cybersecurity:

Q1. In your firm, cybersecurity is:

\footnotetext{
${ }^{6}$ The dataset is not a full panel due to attrition; the overlap between adjacent surveys is at around 80 per cent.
} 
$1=$ Handled by internal resources; $2=$ Outsourced to an external company, belonging to the same group; $3=$ Outsourced to an external company, not belonging to the same group; $4=$ Partly handled by internal resources, partly outsourced; 5 = Not applicable, as no cybersecurity activities exist; 9 = I don't know / I refuse to answer.

Q2. The number of cyber attacks against firms, including small and medium ones, is increasing. Over the last year, how many times were you hit by a cyber attack? Only consider the attacks that had consequences, no matter how limited and/or short-lived and/or easily reversible, on the functioning of the firms' systems and/or on the integrity and confidentiality of data therein stored.

$1=$ No attacks; $2=$ One attack; $3=$ Between 2 and 5 attacks; $4=$ Between 6 and 10 attacks; $5=$ More than 10 attacks; $9=$ I don't know / I refuse to answer.

The questions were included, first and foremost, to address the data gap in the incidence of cyber attacks in the Italian corporate sector. Information on outsourcing was collected to get an initial feel for the way cyber threat is managed by firms and of the market for cybersecurity services in the country. The section on cybersecurity followed others on investments, funding, employment, turnover, international trade, the impact of geopolitical factors on business and government payments to firms. Typically, respondents are either executives or administrative staff with a broad knowledge of the business.

Most results presented in this paper are based on the sample for the 2016 qualitative survey, comprising 4,271 firms. Some require the use of variables that were only collected in the previous quantitative survey, and are computed on a sample restricted to the 3,657 firms that participated in both (Appendix Table A1). ${ }^{7}$

\section{Results: unedited data}

\subsection{Cybersecurity management in Italian non-financial firms}

Nearly all firms report adopting some defensive measure against cyber attacks; only 1.5 per cent have none (Table 1).

Cybersecurity is fully outsourced by 31.8 per cent of respondents and partly outsourced by 26.9 per cent; 37.2 per cent rely on internal resources only. The exclusive use of outsourcing is less common among large and high-tech firms. Involving third parties in securing a firm's IT systems implies giving them at least some access to private data and processes and allowing them to assess vulnerability levels. This is a risk factor per se as some contractors may use the information inappropriately or may not take the necessary precautions to avoid being hacked themselves. Firms that can afford it prefer to have their own security teams; ${ }^{8}$ they may also only outsource the tasks that are considered less sensitive. Indeed, only 5.1 per cent of firms with 500 or more employees choose the option having the highest degree of third-party risk: exclusive outsourcing to a company that is not a part of the same group; for small businesses, the figure is 30.6 per cent.

\footnotetext{
${ }^{7}$ Descriptive statistics for the two samples appear similar (Appendix Table A2); there is no evidence of a systematic discrepancy in model estimation results. Any difference between the stated sample sizes and the number of observations used for estimates depends on item non-response for specific variables included in the regressions, assumed to be unrelated to the analysis variables once all covariates are controlled for.

${ }^{8}$ Data from qualitative surveys consistently confirm that large businesses are more likely to separate cybersecurity from ordinary IT management, employ a Chief Information Security Officer, and other specialized professionals (PriceWaterhouseCoopers, various years).
} 


\section{Cybersecurity management}

Table 1

(percentages)

\begin{tabular}{|c|c|c|c|c|c|c|}
\hline & $\begin{array}{l}\text { Internal } \\
\text { resources }\end{array}$ & $\begin{array}{l}\text { Outsourcing } \\
\text { within group }\end{array}$ & $\begin{array}{l}\text { Outsourcing } \\
\text { outside group }\end{array}$ & $\begin{array}{c}\text { Internal + } \\
\text { outsourcing }\end{array}$ & $\begin{array}{c}\text { No } \\
\text { cybersecurity }\end{array}$ & $\begin{array}{c}\text { Don't know / } \\
\text { No answer }\end{array}$ \\
\hline \multicolumn{7}{|l|}{ Geographical area } \\
\hline North-West & 35.2 & 5.0 & 27.2 & 29.1 & 0.7 & 2.8 \\
\hline North-East & 30.0 & 6.9 & 28.3 & 31.1 & 1.9 & 1.8 \\
\hline Centre & 42.8 & 6.1 & 22.9 & 22.7 & 2.2 & 3.2 \\
\hline South and Islands & 46.8 & 4.1 & 24.1 & 20.1 & 2.0 & 3.0 \\
\hline \multicolumn{7}{|l|}{ Number of employees } \\
\hline $20-49$ & 35.4 & 4.6 & 30.6 & 24.5 & 1.7 & 3.1 \\
\hline $50-199$ & 39.6 & 7.6 & 19.7 & 30.2 & 1.5 & 1.4 \\
\hline $200-499$ & 46.6 & 5.4 & 7.8 & 37.7 & . & 2.5 \\
\hline 500 and over & 42.9 & 10.4 & 5.1 & 36.9 & 0.1 & 4.7 \\
\hline \multicolumn{7}{|l|}{$\begin{array}{l}\text { Tech / knowledge } \\
\text { intensity of sector }(*)\end{array}$} \\
\hline High and medium-high & 43.4 & 5.8 & 19.4 & 27.3 & 0.5 & 3.6 \\
\hline Low and medium-low & 34.9 & 5.5 & 28.7 & 26.7 & 1.9 & 2.3 \\
\hline \multicolumn{7}{|l|}{$\begin{array}{l}\text { Exports as share of } \\
\text { turnover }\end{array}$} \\
\hline Less than $1 / 3$ & 38.2 & 5.5 & 27.0 & 25.0 & 1.8 & 2.6 \\
\hline Between $1 / 3$ and $2 / 3$ & 33.2 & 5.5 & 27.0 & 31.4 & 0.3 & 2.6 \\
\hline Over $2 / 3$ & 37.2 & 5.8 & 20.6 & 31.7 & 1.8 & 3.0 \\
\hline Total & 37.2 & 5.6 & 26.2 & 26.9 & 1.5 & 2.6 \\
\hline
\end{tabular}

(*) High and medium-high: manufacturing firms with high or medium-high technological intensity, and service firms with high knowledge intensity, according to OECD/Eurostat classification. Low and medium-low: all other firms. Firms in the energy sector, not covered by the original classification, are reclassified as high-technology.

The exclusive use of internal resources is more common than average in Southern Italy, at 46.8 per cent. This may depend on the limited availability of potential external contractors: the market for high-tech services is less developed compared to the rest of the country.

Note that, in this wave of the survey, no details are collected on the quality of security measures. Both 'outsourcing' and 'internal resources' may belie an array of vastly different realities. Anecdotal evidence suggests that for smaller, low-tech firms, contractors tend to be retail computer sellers, while internal resources are employees who happen to be IT enthusiasts; in neither case is cybersecurity handled by professionals. On the other hand, larger firms mostly outsource cybersecurity to specialized firms and their internal teams are at least partly staffed by experts. ${ }^{9}$

\subsection{Cyber attacks against Italian non-financial firms}

Despite the avowed existence of defensive measures, almost one business in three (30.3 per cent; Table 2) declares to have fallen prey to a cyber attack in the twelve months prior to the interview; 60.4 per cent

\footnotetext{
${ }^{9}$ A 'knowledge gap' in this field has been documented: demand for security professionals exceeds supply (McAfee and Center for Strategic and International Studies, 2016).
} 
report no attacks; 9.4 per cent do not reply to the question. When estimates are weighted for the number of employees, one of the possible proxies for a firm's contribution to the economy, the overall proportion of self-reported victims climbs to 35.6 per cent. ${ }^{10}$ Among the firms that reported at least one attack, 37.9 per cent were hit only once, 44.5 per cent between two and five times (Appendix Figure A1).

Table 2

\section{Firms hit by at least one cyber attack, unedited data}

(percentages)

\begin{tabular}{|c|c|c|c|c|c|c|}
\hline & \multicolumn{3}{|c|}{ As a share of total firms } & \multicolumn{3}{|c|}{ As a share of total employees } \\
\hline & No attack & $\begin{array}{l}\text { At least one } \\
\text { attack }\end{array}$ & $\begin{array}{l}\text { Don't know/ } \\
\text { No answer }\end{array}$ & No attack & $\begin{array}{l}\text { At least one } \\
\text { attack }\end{array}$ & $\begin{array}{l}\text { Don't know / } \\
\text { No answer }\end{array}$ \\
\hline \multicolumn{7}{|l|}{ Geographical area } \\
\hline North-West & 62.1 & 28.5 & 9.4 & 48.0 & 32.1 & 19.8 \\
\hline North-East & 56.9 & 32.5 & 10.6 & 45.5 & 35.2 & 19.3 \\
\hline Centre & 53.8 & 35.3 & 10.9 & 38.7 & 46.9 & 14.4 \\
\hline South and Islands & 70.0 & 24.4 & 5.6 & 64.0 & 27.1 & 8.9 \\
\hline \multicolumn{7}{|l|}{ Number of employees } \\
\hline $20-49$ & 63.2 & 29.2 & 7.6 & 63.2 & 29.3 & 7.5 \\
\hline $50-199$ & 57.6 & 31.3 & 11.1 & 56.1 & 32.7 & 11.1 \\
\hline $200-499$ & 45.4 & 36.7 & 17.9 & 47.0 & 35.9 & 17.1 \\
\hline 500 and over & 39.3 & 34.8 & 25.9 & 33.0 & 40.7 & 26.3 \\
\hline \multicolumn{7}{|l|}{$\begin{array}{l}\text { Tech / knowledge } \\
\text { intensity of sector }(*)\end{array}$} \\
\hline High and medium-high & 57.3 & 30.5 & 12.1 & 40.0 & 36.8 & 23.2 \\
\hline Low and medium-low & 61.6 & 30.1 & 8.3 & 51.2 & 34.9 & 13.8 \\
\hline \multicolumn{7}{|l|}{$\begin{array}{l}\text { Exports as share of } \\
\text { turnover }\end{array}$} \\
\hline Less than $1 / 3$ & 62.5 & 29.4 & 8.1 & 48.1 & 35.6 & 16.4 \\
\hline Between $1 / 3$ and $2 / 3$ & 54.3 & 34.6 & 11.1 & 44.8 & 38.0 & 17.2 \\
\hline Over $2 / 3$ & 57.1 & 29.0 & 14.0 & 45.8 & 33.0 & 21.2 \\
\hline Total & 60.4 & 30.2 & 9.4 & 47.2 & 35.6 & 17.2 \\
\hline
\end{tabular}

(*) High and medium-high: manufacturing firms with high or medium-high technological intensity, and service firms with high knowledge intensity, according to OECD/Eurostat classification. Low and medium-low: all other firms. Firms in the energy sector, not covered by the original classification, are reclassified as high-technology.

The probability of reporting at least one hit increases with firm size, but it is lower in Southern Italy across all size classes. Larger firms are more attractive to all types of attackers: they handle more data and this data is also likely to be more valuable. They are also more exposed, as they are better known, and they have more devices connected to the Internet, wider networks, more employees that can engage in risky behaviour and more external suppliers that may have some access to IT assets. On the other hand, firms

\footnotetext{
${ }^{10}$ Results are similar when data are weighted by turnover.
} 
located in the South tend to have lower levels of productivity, knowledge content and technology use: they are less interesting and less visible to hackers. ${ }^{11}$

There is a link between internationalization and attacks: firms that export between one third and two thirds of their products or services are more likely to report a hit compared to the average. Again, exposure probably plays a role. Cyber attacks are often cross-border: firms that exchange information with business partners abroad, especially in high-risk jurisdictions, are more likely to become targets compared to others who do not communicate through the Internet as often, and whose existence may not even be known outside their immediate surroundings. While the argument should apply even more so for firms that export more than two thirds of total turnover, this does not seem to be true when looking at the unedited data: the comparison may be affected by the fact that non-response is higher for this latter group (see below).

\section{Data correction models}

While already somewhat informative, estimates based on the unedited data should be viewed with great caution. The literature suggests that two important sources of downward bias exist when measuring the incidence of cyber attacks via surveys: imperfect knowledge of the phenomenon on the part of some respondents and reticence on the part of others (Moore and Anderson, 2011).

Some firms may lack the technical ability required to realize that they have been hit. Only some types of attacks, generally aimed at intimidation or extortion, are designed to be evident; those aimed at data exfiltration, or any other remote exploitation of a computer's resources, are built to be as unobtrusive as possible and require specific skills to be detected. ${ }^{12}$

Other firms, while competent enough to recognize attacks, may decline to disclose them: this type of information could be considered too sensitive to be shared, no matter how many confidentiality guarantees are given, as it potentially implies reputational damage, loss of business, legal fees, regulatory fines, and other costly consequences.

Table 3 shows the results of two logistic regressions, respectively addressing the probability of answering the question on cyber attacks and the probability of reporting at least one hit. Covariates include the geographical, size, sector and export descriptors shown in Table 2; a dummy that distinguishes between industrial and service firms; two indicators derived from a paradata section at the end of the survey wherein respondents are asked to state whether completing the questionnaire was difficult for them and whether gathering relevant information from different sources (e.g. different offices in the company, third-party suppliers) was a problem. The regressions are run both on the full sample and on the restricted sample, where

\footnotetext{
${ }^{11}$ In all descriptive tables, firms from Central Italy show a higher hit rate. This is a spurious result: respondents are allocated to geographical areas based on their legal headquarters, and most formerly state-owned large corporations (railways, postal services, etc.) are headquartered in Rome. These firms are among the most targeted, both because they operate in strategic sectors and because of their size. In regressions where such factors are controlled for, the results from Central Italy are similar to those observed for Northern regions.

12 Median time to detection of such attacks has been estimated at over one year for European business, vis-à-vis five months for US ones (Mandiant, 2016).
} 
an additional variable measuring the share of skilled labour over total labour input is available. ${ }^{13}$ Indicators of outsourcing are not included as they yield results that are not robust across specifications: this may depend on unobserved heterogeneity in the quality of contractors and/or internal resources.

Table 3

\section{Probability of answering the question on cyber attacks vis-à-vis probability of reporting at least one attack (unedited data), by type of firm}

(logistic regressions)

\begin{tabular}{|c|c|c|c|c|}
\hline & \multicolumn{2}{|c|}{ Full sample } & \multicolumn{2}{|c|}{ Restricted sample } \\
\hline & Answered? & Reported attack? & Answered? & Reported attack? \\
\hline Intercept & $\begin{array}{rl}2.277 & * * * \\
(0.159) & \end{array}$ & $\begin{array}{l}-0.801 \quad * * * \\
(0.112)\end{array}$ & $\begin{array}{r}2.518 \text { *** } \\
(0.198)\end{array}$ & $\begin{array}{l}-1.150 * * * \\
(0.137)\end{array}$ \\
\hline Small & $\begin{array}{r}0.201 \quad * * * \\
(0.055)\end{array}$ & $\begin{array}{l}-0.091 \quad * * \\
(0.037)\end{array}$ & $\begin{array}{rl}0.200 & * * * \\
(0.061) & \end{array}$ & $\begin{array}{l}-0.086 * * \\
(0.041)\end{array}$ \\
\hline South & $\begin{array}{r}0.260 \quad * * * \\
(0.086)\end{array}$ & $\begin{array}{l}-0.205 \quad * * * \\
(0.048)\end{array}$ & $\begin{array}{rl}0.242 & * * * \\
(0.094) & \end{array}$ & $\begin{array}{l}-0.212 \quad * * * \\
(0.053)\end{array}$ \\
\hline High-tech sector & $\begin{array}{l}-0.171 \quad * * * \\
(0.057)\end{array}$ & $\begin{array}{r}0.032 \\
(0.040)\end{array}$ & $\begin{array}{r}-0.078 \\
(0.066)\end{array}$ & $\begin{array}{r}-0.019 \\
(0.045)\end{array}$ \\
\hline Industrial & $\begin{array}{r}0.246 \text { *** } \\
(0.062)\end{array}$ & $\begin{array}{l}-0.088 * * \\
(0.038)\end{array}$ & $\begin{array}{r}0.196 \text { *** } \\
(0.071)\end{array}$ & $\begin{array}{r}-0.006 \\
(0.044)\end{array}$ \\
\hline Export share: over $2 / 3$ & $\begin{array}{l}-0.304 \quad * * * \\
(0.101)\end{array}$ & $\begin{array}{r}-0.053 \\
(0.075)\end{array}$ & $\begin{array}{l}-0.352 \quad * * * \\
(0.109)\end{array}$ & $\begin{array}{r}-0.115 \\
(0.083)\end{array}$ \\
\hline Export share: between $1 / 3$ and $2 / 3$ & $\begin{array}{r}-0.057 \\
(0.095)\end{array}$ & $\begin{array}{r}0.176 \text { *** } \\
(0.066)\end{array}$ & $\begin{array}{r}-0.026 \\
(0.103)\end{array}$ & $\begin{array}{rl}0.244 & * * * \\
(0.072) & \end{array}$ \\
\hline Found survey difficult & $\begin{array}{l}-0.380 \quad * * * \\
(0.081)\end{array}$ & $\begin{array}{r}0.060 \\
(0.065)\end{array}$ & $\begin{array}{l}-0.340 \quad * * * \\
(0.089)\end{array}$ & $\begin{array}{r}0.108 \\
(0.069)\end{array}$ \\
\hline Multiple respondents involved & $\begin{array}{l}-2.049 * * * \\
(0.522)\end{array}$ & $\begin{array}{r}0.695 * \\
(0.378)\end{array}$ & $\begin{array}{l}-2.046 \quad * * * \\
(0.573)\end{array}$ & $\begin{array}{r}0.768 * \\
(0.422)\end{array}$ \\
\hline Share skilled & & & $\begin{array}{l}-0.430 \quad * * \\
(0.218)\end{array}$ & $\begin{array}{rl}0.709 & * * * \\
(0.144) & \end{array}$ \\
\hline $\mathrm{N}$ & 4254 & 3742 & 3657 & 3225 \\
\hline Percent concordant & 66.3 & 57.5 & 66.6 & 58.2 \\
\hline Percent discordant & 32.6 & 41.3 & 32.5 & 41.1 \\
\hline Percent tied & 1.1 & 1.2 & 0.9 & 0.7 \\
\hline
\end{tabular}

Levels of statistical significance of coefficients : *** 1\%** 5\%*10\%

The regressions have limited explanatory power with respect to the reported hit rate: this is fully expected as the survey does not provide any information on defensive measures adopted by firms, an important component of micro-level vulnerability. Still, two distinct clusters emerge quite clearly, corresponding to the two sources of bias described above. Firms where human capital is typically lower than average - small ones, those active in traditional sectors, and again those located in the South -answer the

\footnotetext{
${ }^{13}$ For a full description of the variables used, see Appendix Table A3.
} 
cybersecurity question more often than the rest, but report fewer attacks. The result holds true even after controlling for self-assessed questionnaire difficulty, which is negatively correlated with response rates (although it is not a significant predictor of reported hit rates). This group of firms probably lacks the technical skills necessary for attack detection.

On the other hand, large businesses have the lowest response rates and the highest hit rates. The same applies to firms with a high share of skilled labour ${ }^{14}$ and to those where multiple respondents were involved in answering the survey, a possible proxy for organizational complexity; high-tech firms and those engaging in cross-border business show similar behaviour too, although not all the effects are statistically significant, possibly on account of collinearity. This group is likely to be at least somewhat reticent.

In order to correct for these issues, we need to understand the determinants of both response behaviour and the probability of being attacked so that we can impute missing data and edit unreliable data based on models. As a first step, we formalize the response process (Figure 1). There are two possible true states of the world: either a firm has been attacked or it has not. Given a state, respondents can observe it or not. After observing it, they can tell the truth or lie when reporting it, or refuse to answer the question.

Figure 1

\section{Cyber attacks: response process}

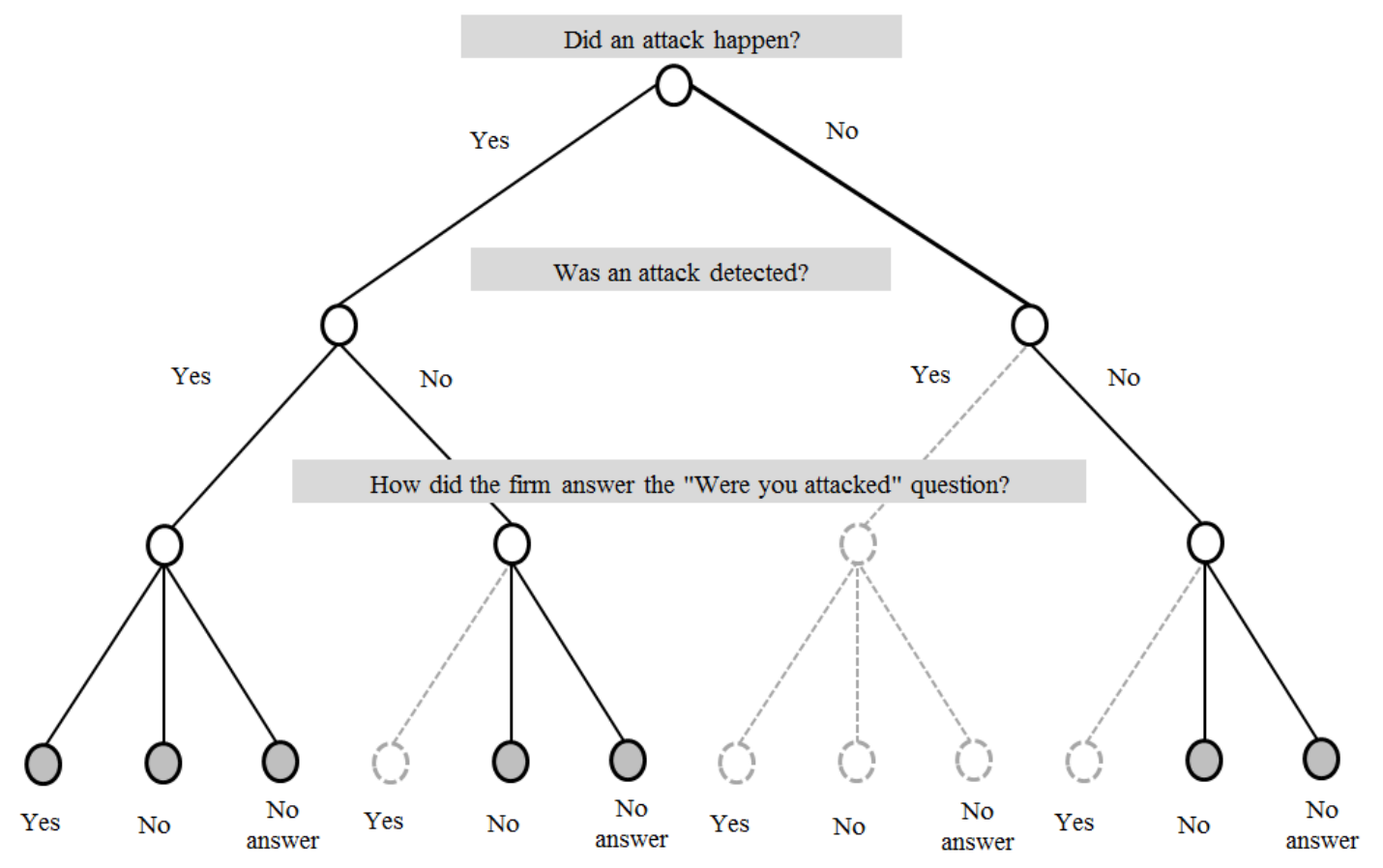

\footnotetext{
${ }^{14}$ This variable, only available for the restricted sample, is a better predictor in most regressions compared to the technology level of the firm's sector of activity, probably because it accounts for otherwise unobserved cross-sectional variation in knowledge intensity.
} 
Of the twelve outcomes that emerge by combining the possibilities, the seven shaded ones are realistic; the others appear unlikely enough to be neglected. ${ }^{15}$ A negative answer to the survey question can therefore correspond to three different cases: no attacks, an undetected attack, or a detected attack that was deliberately misreported. Non-response can correspond to no attacks, an undetected attack, or a detected attack that was not reported. A positive answer is observed only if an attack happened and was detected.

We propose four data correction models (Table 4). In the base model, we only impute data for nonrespondents. In augmented model A, we delete answers for respondents who reported no attacks and who fit a chosen criterion for low detection ability, then impute data for both them and non-respondents. In model B, we delete answers for respondents who reported no attacks and fit a chosen criterion for likelihood of misreporting, then impute data for both them and non-respondents. Model $\mathrm{C}$ combines the two corrections.

Table 4

\section{Cyber attacks: data correction models}

\begin{tabular}{|c|c|c|c|c|}
\hline \multirow[b]{2}{*}{ Model } & \multicolumn{3}{|c|}{ Corrects for... } & \multirow[b]{2}{*}{ Data imputed for... } \\
\hline & $\begin{array}{l}\text { Non- } \\
\text { response }\end{array}$ & $\begin{array}{c}\text { Mis- } \\
\text { detection }\end{array}$ & $\begin{array}{l}\text { Mis- } \\
\text { reporting }\end{array}$ & \\
\hline Base & Yes & $\mathrm{No}$ & $\mathrm{No}$ & Non-respondents \\
\hline Augmented A & Yes & Yes & No & $\begin{array}{l}\text { Non-respondents; respondents with no knowledge of TTIP } \\
\text { who reported no attacks }\end{array}$ \\
\hline Augmented B & Yes & $\mathrm{No}$ & Yes & $\begin{array}{l}\text { Non-respondents, foreign-controlled respondents who } \\
\text { reported no attacks }\end{array}$ \\
\hline Augmented C & Yes & Yes & Yes & $\begin{array}{l}\text { Non-respondents, respondents with no knowledge of TTIP } \\
\text { who reported no attacks, foreign-controlled respondents who } \\
\text { reported no attacks }\end{array}$ \\
\hline
\end{tabular}

In model A, we instrument low detection ability with the answer to a question that measures the level of knowledge of the Transatlantic Trade and Investment Partnership (TTIP). ${ }^{16}$ This variable is exogenous to the probability of suffering a cyber breach, however respondents who state that they never heard of TTIP are significantly less likely to report an attack compared to the rest (Appendix Table A4). The negotiations for this treaty were mentioned often in the media in the recent past as the fieldwork for the survey was underway: not knowing anything about them is tantamount to not following TV news and not reading

\footnotetext{
${ }^{15}$ Cases where no attack was observed, but one was reported are unlikely because a respondent convinced that a negative event did not take place has no incentive to report otherwise. Cases where no attack happened, but one was observed may correspond to technical failures mistaken for attacks; we assume them to be infrequent.

${ }^{16}$ The question, administered in the same survey, reads as follows:

What do you know of the negotiations currently underway between the United States and the European Union on the agreement on trade and investment known as TTIP (Transatlantic Trade and Investment Partnership)? $1=1$ didn't know that this negotiation existed; $2=I$ heard about the negotiation, but I don't know the contents; $3=1$ have some knowledge of the general contents of the agreement $4=1$ have detailed knowledge of some aspects of the agreement; $9=1$ don't know/I refuse to answer.
} 
newspapers. Assuming that general knowledge is correlated to knowledge of cyber threats, we can take the answer to this question as associated with attack detection skills.

In model B, we instrument the likelihood of misreporting with a dummy variable that is valued at one if the self-reported effective locus of control of the firm is outside Italy. ${ }^{17}$ This characteristic should be exogenous to the probability of being attacked or, if anything, correlate positively with it, in the same vein of large businesses and exporters: multi-national enterprises might be more interesting, and more exposed, to hackers. On the contrary, foreign-controlled firms report lower hit rates. They also answer less often, suggesting that this is not a case of better defences compared to similar domestic firms (Appendix Table A5).

The pattern can be understood by looking at the issue from a national security perspective. Governments are trying to raise awareness of cyber threats in the business community: widespread vulnerability is seen as an existential risk, especially as economically motivated cyber espionage becomes more common. In most OECD countries, the state offers guidance to firms, ${ }^{18}$ highlighting the importance of defending against terrorists and competitors alike. A firm operating in a foreign country might prefer to share information on cyber attacks with its own national government, understating vulnerability to public authorities (and surveyors) in the host country instead.

All imputations are performed based on the same specification. A dummy variable, valued at one if the firm reported an attack, is regressed on the set of covariates presented in Table $3 ;^{19}$ the regression coefficients are used to compute a probability score for each firm for which the answer was originally missing or has been deleted; a Bernoulli draw is performed from a distribution with the score as the mean, and the outcome is the imputed value. ${ }^{20}$ The correction models only differ from each other in that they are estimated on different data sets: the base version uses all responses provided in the survey, while the others exclude the deleted categories starting from the estimation stage.

\section{Results: corrected data}

Table 5 shows a summary of results for all data correction models, and also of versions thereof where non-respondents are assumed to be reticent, so that data that were originally missing are imputed as reported attacks independent of what the model predicts. ${ }^{21}$

\footnotetext{
${ }^{17}$ Answer to this question, administered in the same survey:

Control of the business, i.e. dominant influence on strategic decisions, is exercised by a person or company whose nationality is: 1 = Italian; 2 = Foreign

${ }^{18}$ See, for example, the National Cybersecurity Awareness Month promoted by the US Department of Homeland Security, or the CyberAware campaign launched by the UK government.

${ }^{19}$ Standard imputation theory predicts that non-response bias can be corrected only if the data are missing at random (MAR), i.e. if the non-response pattern is not correlated with the value of the analysis variable, but with variables included in the imputation model. Data can be still treated as MAR if a set of covariates exists that predicts both response probability and the value of the analysis variable, i.e. if the non-response pattern is likely to be uncorrelated with the value of the analysis variable after controlling for those covariates (Little and Rubin, 2002).

${ }^{20}$ In order to control for this element of randomness, five separate draws are made and averaged.

${ }^{21}$ The results are robust across many possible specifications, not presented in this paper for the sake of brevity. Some imputation diagnostics are available in Appendix Table A6.
} 
Table 5

Firms hit by at least one cyber attack: summary across data correction models (percentages)

\begin{tabular}{|c|c|c|c|c|c|c|c|}
\hline & $\begin{array}{c}\text { Complete } \\
\text { cases }\end{array}$ & Base (i) & Base (ii) & $A(i)$ & $A(i i)$ & $B$ & $C$ \\
\hline Share of firms & 33.3 & 33.8 & 33.3 & 39.7 & 39.2 & 34.5 & 41.2 \\
\hline ...if all non-respondents attacked & I & 39.6 & 39.2 & 45.2 & 44.9 & 40.8 & 45.8 \\
\hline Share of employees & 43.0 & 43.7 & 44.8 & 47.6 & 47.9 & 49.0 & 52.7 \\
\hline ...if all non-respondents attacked & l & 52.7 & 52.9 & 56.0 & 56.3 & 56.4 & 59.9 \\
\hline $\mathrm{N}$ & 3,742 & 4,254 & 3,657 & 4,254 & 3,657 & 3,657 & 3,657 \\
\hline
\end{tabular}

(i) Estimated on full sample (ii) Estimated on restricted sample

The first column in the table is provided for reference and shows results for complete cases only, i.e. firms that provided an answer to the question on cyber attacks. This equates to assuming that the distribution of the analysis variable is the same across respondents and non-respondents. In this scenario, the share of firms hit by attacks goes up by three percentage points, to 33.3 per cent ( 43 per cent of employees), from the 30.2 per cent observed on unedited data.

The base imputation model yields results that are very similar: by construction, it is bound to reproduce all sources of bias present in the unedited data. The misdetection correction is quite significant, with the share of attacked firms climbing to over 39 per cent (48 per cent of employees) under model A for both the full and the restricted sample; the misreporting correction has a smaller effect. The two combined yield a hit rate of 41.2 per cent (52.7 per cent of employees). If the reticence correction is added, the share of attacked firms increases by 4.5-6.5 percentage points, depending on the model.

We believe that model $\mathrm{A}$ is the most informative: ${ }^{22}$ it can be estimated on the largest possible sample and the instrument used to single out unreliable answers is more strongly exogenous compared to the one used in model B. ${ }^{23}$ Also, we believe that non-response should be treated as reticence: the survey offers the option to report no attacks, and there are few reasons why a firm should skip the item other than not wanting to disclose breaches. ${ }^{24}$ Detailed results derived by applying model A to the data and then adding the reticence correction are presented in Table 6. In this scenario, 45.2 per cent of firms, corresponding to 56 per cent of employees, have been hit by at least one cyber attack.

\footnotetext{
${ }^{22}$ Sample selection due to item non-response in covariates for models B and C is especially difficult to control.

${ }^{23}$ The results are robust to different specifications of the instrument. In the version of model A presented in this paper, only those respondents who declared no knowledge at all of TTIP are included in the group that is assumed to have low detection ability; if we expand this group to encompass those who reported very generic knowledge ('I heard about the negotiation, but I don't know the contents'), thus adding variance in terms of covariates included in the model, the effects shown in Table 4A and Table 7 obtain again; in some cases, they are even stronger. We choose to describe the narrow specification, as it keeps the share of deleted cases relatively low.

${ }^{24}$ Under a no-reticence hypothesis, the non-response rate for the question on attacks should roughly coincide with that observed for the question on outsourcing, whereas it is multiplied by a factor of 3.6 on average, and more than 5 for the largest firms.
} 
Results confirm some features of the distribution observed on the unedited data: cyber attacks are more common among larger firms (62.8 per cent of those with 500 employees and over), while they are less frequent in Southern regions (35.9 per cent). Other patterns emerge or become more starkly defined: hightech firms are more likely to be attacked than their low-tech counterparts, with hit rates at 48.8 and 43.8 per cent respectively, and all exporters fare worse than non-exporters.

Table 6

Firms hit by at least one cyber attack: data corrected for misdetection, reticence (percentages; estimates on full sample)

\begin{tabular}{|c|c|c|c|c|c|}
\hline & Share of firms & $\begin{array}{c}\text { Total correction } \\
\text { (percentage points) }\end{array}$ & $\begin{array}{l}\text { Misdetection (share } \\
\text { of total correction) }\end{array}$ & $\begin{array}{l}\text { Reticence (share of } \\
\text { total correction) }\end{array}$ & Share of employees \\
\hline \multicolumn{6}{|l|}{ Geographical area } \\
\hline North-West & 44.2 & 15.7 & 40.1 & 59.9 & 54.8 \\
\hline North-East & 47.3 & 14.8 & 28.4 & 71.6 & 57.5 \\
\hline Centre & 52.3 & 17.0 & 35.9 & 64.1 & 63.9 \\
\hline South and Islands & 35.9 & 11.5 & 51.3 & 48.7 & 42.6 \\
\hline \multicolumn{6}{|l|}{ Number of employees } \\
\hline $20-49$ & 42.7 & 13.5 & 43.7 & 56.3 & 44.0 \\
\hline $50-199$ & 48.4 & 17.1 & 35.1 & 64.9 & 48.2 \\
\hline $200-499$ & 56.0 & 19.3 & 7.3 & 92.7 & 56.2 \\
\hline 500 and over & 62.8 & 28.0 & 7.5 & 92.5 & 67.6 \\
\hline \multicolumn{6}{|l|}{$\begin{array}{l}\text { Tech / knowledge } \\
\text { intensity of sector }(*)\end{array}$} \\
\hline High and medium-high & 48.8 & 18.3 & 33.9 & 66.1 & 62.7 \\
\hline Low and medium-low & 43.8 & 13.7 & 39.4 & 60.6 & 52.4 \\
\hline \multicolumn{6}{|l|}{$\begin{array}{l}\text { Exports as share of } \\
\text { turnover }\end{array}$} \\
\hline Less than $1 / 3$ & 43.0 & 13.6 & 40.4 & 59.6 & 55.1 \\
\hline Between $1 / 3$ and $2 / 3$ & 51.8 & 17.2 & 35.5 & 64.5 & 59.2 \\
\hline Over $2 / 3$ & 48.5 & 19.5 & 28.2 & 71.8 & 57.6 \\
\hline Total & 45.2 & 15.0 & 37.3 & 62.7 & 56.0 \\
\hline
\end{tabular}

(*) High and medium-high: manufacturing firms with high or medium-high technological intensity, and service firms with high knowledge intensity, according to OECD/Eurostat classification. Low and medium-low: all other firms. Firms in the energy sector, not covered by the original classification, are reclassified as high-technology.

On average, the correction implies an increase of 15 percentage points in the incidence of attacks; the figure is higher for the categories that were more severely affected by non-response. Misdetection accounts for 37.3 per cent of total correction; the incidence is highest in the South (51.3 per cent) and for firms with less than 50 employees (43.7 per cent), while it is lowest for large businesses. Most of these characteristics are a direct consequence of how the corrections were constructed; the core messages are, however, quite robust across different specifications (see Appendix Tables A7-A11).

When the regression models presented in Table 3 are estimated on imputed data, the results obtained on the unedited data are confirmed and the predictive power improves for both specifications (Table 7, columns 
$i$ and $i i) .{ }^{25}$ Self-assessed questionnaire difficulty also appears to be a strong predictor of the probability of being hit: this is, in all likelihood, a spurious effect due to the reticence correction.

Table 7

\section{Probability of being hit by least one attack (imputed data), by type of firm}

(logistic regressions)

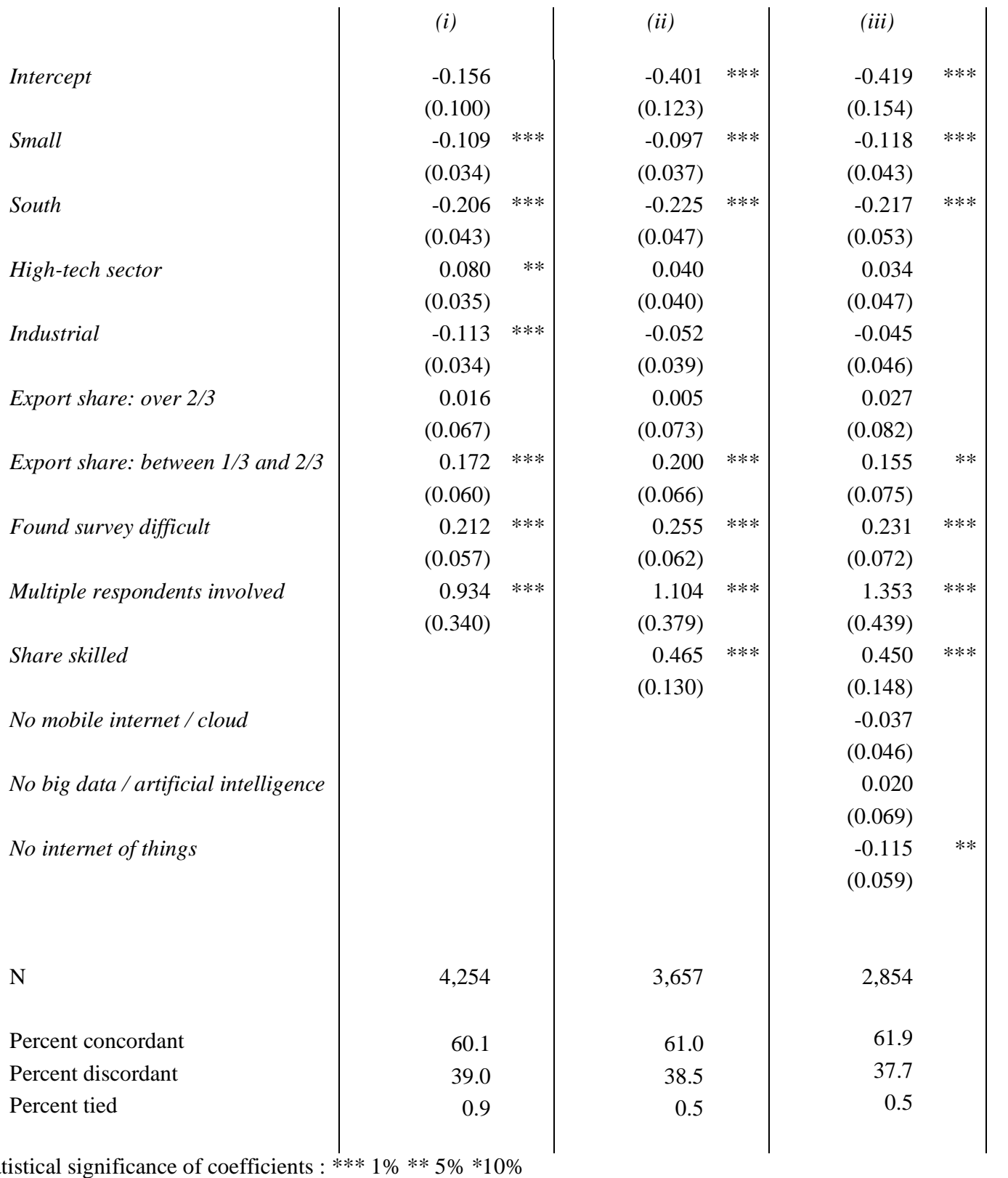

Levels of statistical significance of coefficients : *** $1 \% * * 5 \% * 10 \%$

We run one further regression to take into account a few variables on technology adoption (Table 7, column iii); the results should be taken as merely indicative, as the information is only available for a

\footnotetext{
${ }^{25}$ The effect of exporting over two thirds of turnover now has the expected sign, but is still not statistically significant. We were not been able to find a convincing explanation for this result: while there are hints that the incidence of lowtech firms in the textile sector in this group plays a role, no specification was robustly significant. Further data are needed to understand which type of heterogeneity is at play.
} 
fraction of the sample and there is no way to control the selection process. Firms that use IoT devices have a higher probability of being attacked: this could be because of specific vulnerabilities or because this characteristic proxies for aspects of the firm's technological sophistication that are captured neither by the activity sector nor by the share of skilled labour over total labour. As IoT-based attacks are still relatively rare compared to other forms, it is probably a mix of the two. The effect of other technologies is not statistically significant, probably on account of limited variation in the sample.

Even after all corrections, the economy-wide risk level is likely to be higher than we estimated. The financial sector is traditionally not covered in the survey because central banks, in their capacity as regulators and supervisors, are already in possession of detailed data. ${ }^{26}$ Health care, education and social care are also excluded because in Italy they are mostly provided by the state. Results from the UK governmental survey mentioned in Section 1 suggest that these sectors are more profitable targets to hackers compared to the average and can be expected to show higher hit rates. ${ }^{27}$

\section{Conclusions}

In this paper, we have presented preliminary evidence on cyber risk in the Italian private sector based on a representative sample of industrial and non-financial service firms with 20 employees or more. Only 1.5 per cent of respondents stated that they do not take any cybersecurity measures, showing that at least some awareness of cyber risk permeates the economy; however, significant vulnerability still emerged. About one third of firms reported at least some damage from cyber attacks, in terms of operational continuity and/or integrity and confidentiality of business data, between September 2015 and September 2016.

Once data are corrected to take into account the fact that some respondents may not be aware of having been attacked, and others may be reticent in disclosing what is perceived as sensitive information, the share of attacked firms climbs to 45.2 per cent (56 per cent of total employment). Attack rates are lowest for firms headquartered in Southern Italy, at 39.5 per cent, and highest for those with more than 500 employees, at 62.8 per cent.

Along with large firms, those in high-tech sectors, those employing a high share of skilled labour and those with a significant degree of international exposure are more likely to be hit. These businesses are both more visible and more attractive to attackers compared to the rest; not only are they better known and more present online than average, they also tend to handle larger amounts of valuable data.

The paper does not assess two policy-relevant dimensions: the correlation between firm-level vulnerability and investments in cyber defence, and the cost of cyber breaches. Further research is needed on both subjects as more data become available.

\footnotetext{
${ }^{26}$ On the subject of cybersecurity, the European Central Bank recently conducted a thorough investigation, although most results are confidential.

27 Studies from the private sector, although not statistically representative, also confirm this fact: see for example KPMG (2015) for the health care industry, and VMWare (2016) for higher education.
} 
Appendix 
Table A1

Sample composition

(number of firms)

\begin{tabular}{|c|c|c|c|c|c|c|}
\hline & \multicolumn{3}{|c|}{ Full sample } & \multicolumn{3}{|c|}{ Restricted sample } \\
\hline & Industrial & Service & All & Industrial & Service & All \\
\hline \multicolumn{7}{|l|}{ Geographical area } \\
\hline North-West & 757 & 288 & 1,045 & 656 & 247 & 903 \\
\hline North-East & 622 & 262 & 884 & 515 & 202 & 717 \\
\hline Centre & 675 & 269 & 944 & 585 & 231 & 816 \\
\hline South and Islands & 988 & 400 & 1,388 & 891 & 336 & 1,227 \\
\hline \multicolumn{7}{|l|}{ Number of employees } \\
\hline $20-49$ & 1,103 & 394 & 1,497 & 952 & 327 & 1,279 \\
\hline $50-199$ & 1,215 & 454 & 1,669 & 1,056 & 365 & 1,421 \\
\hline $200-499$ & 443 & 182 & 625 & 392 & 163 & 555 \\
\hline 500 and over & 281 & 189 & 470 & 247 & 161 & 408 \\
\hline \multicolumn{7}{|c|}{ Tech / knowledge intensity of sector } \\
\hline High and medium-high & 985 & 244 & 1,229 & 860 & 204 & 1,064 \\
\hline Low and medium-low & 2,057 & 975 & 3,032 & 1,787 & 812 & 2,599 \\
\hline \multicolumn{7}{|l|}{ Exports as share of turnover } \\
\hline Less than $1 / 3$ & 1,506 & 1,090 & 2,596 & 1,313 & 905 & 2,218 \\
\hline Between $1 / 3$ and $2 / 3$ & 823 & 83 & 906 & 713 & 71 & 784 \\
\hline Over $2 / 3$ & 713 & 46 & 759 & 616 & 39 & 655 \\
\hline Total & 3,042 & 1,219 & 4,261 & 2,647 & 1,016 & 3,663 \\
\hline
\end{tabular}

Table A2

Firms hit by at least one cyber attack, unedited data, restricted sample (percentages)

\begin{tabular}{|c|c|c|c|c|c|c|}
\hline & \multicolumn{3}{|c|}{ As a share of total firms } & \multicolumn{3}{|c|}{ As a share of total employees } \\
\hline & No attack & $\begin{array}{l}\text { One attack } \\
\text { or more }\end{array}$ & $\begin{array}{l}\text { Don't know/ } \\
\text { No answer }\end{array}$ & No attack & $\begin{array}{c}\text { At least one } \\
\text { attack }\end{array}$ & $\begin{array}{l}\text { Don't know / } \\
\text { No answer }\end{array}$ \\
\hline \multicolumn{7}{|l|}{ Geographical area } \\
\hline North-West & 61.5 & 28.8 & 9.7 & 47.7 & 32.1 & 20.2 \\
\hline North-East & 56.9 & 31.7 & 11.4 & 44.9 & 36.5 & 18.6 \\
\hline Centre & 55.0 & 35.4 & 9.6 & 38.4 & 47.7 & 13.8 \\
\hline South and Islands & 71.5 & 22.9 & 5.6 & 65.0 & 26.6 & 8.4 \\
\hline \multicolumn{7}{|l|}{ Number of employees } \\
\hline $20-49$ & 63.4 & 29.0 & 7.6 & 63.4 & 29.1 & 7.6 \\
\hline $50-199$ & 58.9 & 30.1 & 11.0 & 57.6 & 31.6 & 10.7 \\
\hline $200-499$ & 44.4 & 37.2 & 18.4 & 46.2 & 36.3 & 17.5 \\
\hline 500 and over & 38.4 & 36.0 & 25.7 & 32.3 & 42.5 & 25.3 \\
\hline \multicolumn{7}{|c|}{$\begin{array}{l}\text { Tech / knowledge intensity of sector } \\
(*)\end{array}$} \\
\hline High and medium-high & 57.9 & 30.6 & 11.5 & 39.1 & 37.5 & 23.4 \\
\hline Low and medium-low & 61.9 & 29.5 & 8.6 & 51.5 & 35.3 & 13.2 \\
\hline \multicolumn{7}{|c|}{ Exports as share of turnover } \\
\hline Less than $1 / 3$ & 63.2 & 28.7 & 8.1 & 48.0 & 36.5 & 15.5 \\
\hline Between $1 / 3$ and $2 / 3$ & 52.9 & 36.1 & 11.0 & 43.9 & 38.4 & 17.8 \\
\hline Over $2 / 3$ & 58.0 & 27.5 & 14.5 & 45.9 & 31.9 & 22.2 \\
\hline Total & 60.8 & 29.8 & 9.4 & 47.0 & 36.1 & 16.9 \\
\hline
\end{tabular}




\section{Number of cyber attacks}

(percentage of firms that reported at least one attack)

$$
=1 \backsim 2-5 \quad \square-10 \quad \square>10
$$

a. All

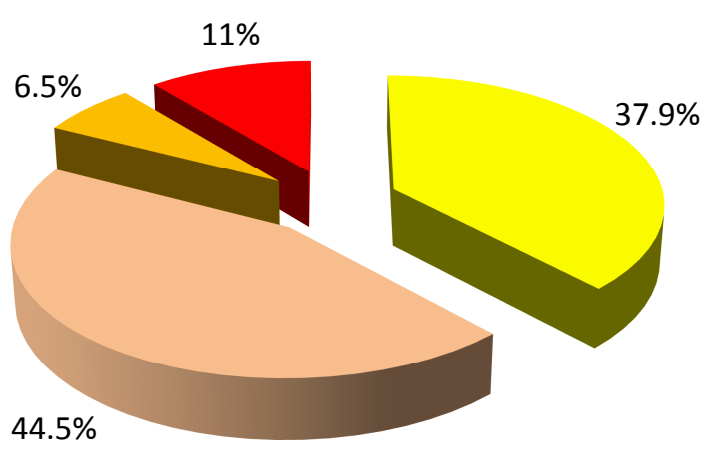

c. By firm size

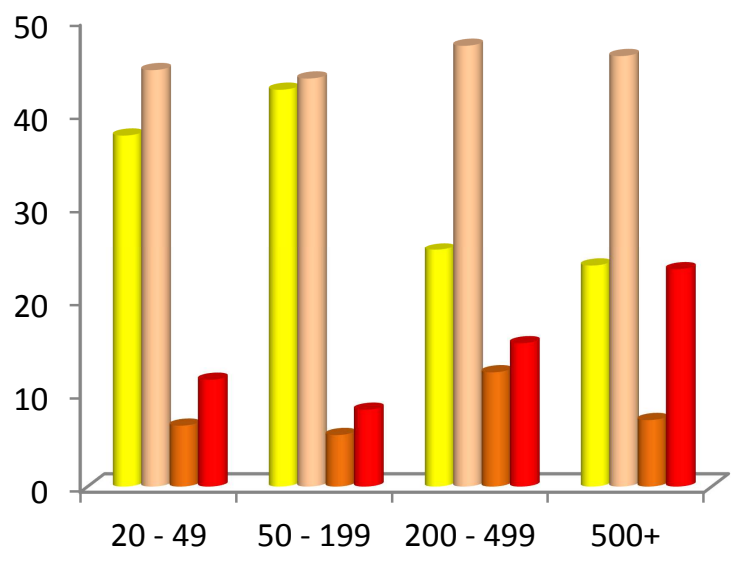

b. By geographical area

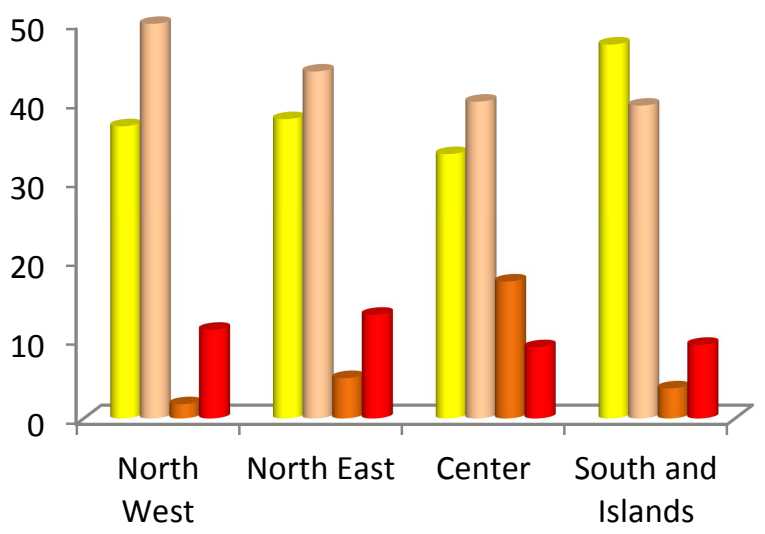

d. By technology level

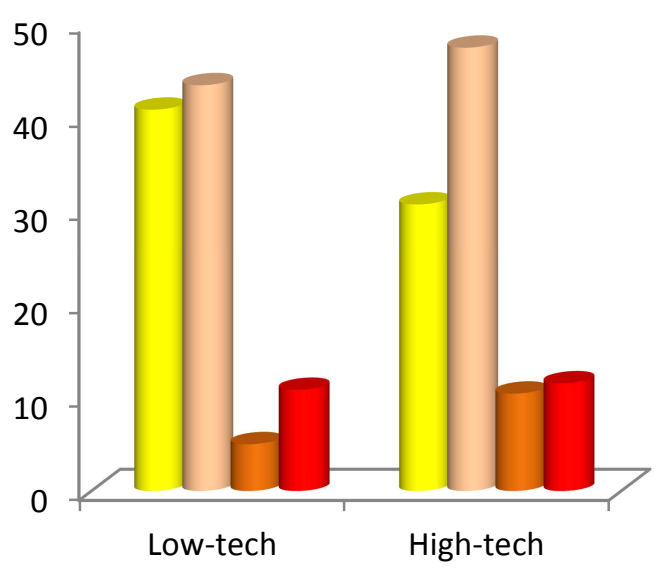


Table A3

\section{Definition of variables used in regressions}

\begin{tabular}{|c|c|}
\hline Descriptor & Type \\
\hline Small & Binary \\
\hline South & Binary \\
\hline High-tech & Binary \\
\hline Industrial & Binary \\
\hline Export share & Multinomial \\
\hline Found survey difficult & Binary \\
\hline $\begin{array}{l}\text { Multiple information } \\
\text { sources }\end{array}$ & Continuous \\
\hline No outsourcing & Binary \\
\hline No knowledge of TTIP & Binary \\
\hline Share skilled & Continuous \\
\hline Foreign control & Binary \\
\hline
\end{tabular}

Content

Number of employees between 20 and 49, 2015 average

Administrative headquarters located in Southern Italy or Islands, as of September 2016

Main activity sector in 2016 classified by OECD/Eurostat as high or medium-high technological intensity (manufacturing), or high knowledge intensity (services). Energy sector not considered by OECD/Eurostat, classified as high-tech.

ATECO activity sector as of September 2016: manufacturing, mining, energy

Value of exported goods or services as a fraction of turnover, 2016 (expectation as of September 2016)

Self-assessed difficulty of the 2016 qualitative questionnaire: 'High' or 'Excessive'

Share of self-assessed difficulty of 2016 the qualitative questionnaire dependent on having to retrieve information from multiple sources

Self-reported cybersecurity management through internal resources only

Self-reported knowledge of TTIP negotiation: 'I did not know that this negotiation existed'

Share of employees that are not apprentices, trainees, or manual workers over average employment, 2016

Self-reported locus of decision making for the firm in 2016: outside Italy 
Table A4

Probability of answering the question on cybersecurity vis-à-vis probability of being attacked (logistic regressions)

\begin{tabular}{|c|c|c|c|c|c|}
\hline & \multicolumn{2}{|c|}{ Full sample } & \multicolumn{3}{|c|}{ Restricted sample } \\
\hline & Answered? & Reported attack? & Answered? & Reported attac & $c k ?$ \\
\hline Intercept & $\begin{array}{r}2.929 * * \\
(0.217)\end{array}$ & $\begin{array}{l}-0.816 \quad * * * \\
(0.120)\end{array}$ & $\begin{array}{r}3.386 \text { *** } \\
(0.271)\end{array}$ & $\begin{array}{l}-1.277 \\
(0.155)\end{array}$ & \\
\hline Small & $\begin{array}{r}0.351 * * \\
(0.067)\end{array}$ & $\begin{array}{l}-0.107 \quad * * * \\
(0.039)\end{array}$ & $\begin{array}{r}0.348 \text { *** } \\
(0.074)\end{array}$ & $\begin{array}{r}-0.104 \\
(0.044)\end{array}$ & $* *$ \\
\hline South & $\begin{array}{r}0.533 * * \\
(0.128)\end{array}$ & $\begin{array}{l}-0.183 \text { *** } \\
(0.051)\end{array}$ & $\begin{array}{r}0.501 \text { *** } \\
(0.139)\end{array}$ & $\begin{array}{l}-0.185 \\
(0.056)\end{array}$ & $* * *$ \\
\hline High-tech sector & $\begin{array}{l}-0.175 * * \\
(0.070)\end{array}$ & $\begin{array}{r}0.017 \\
(0.042)\end{array}$ & $\begin{array}{r}-0.070 \\
(0.079)\end{array}$ & $\begin{array}{r}-0.037 \\
(0.047)\end{array}$ & \\
\hline Industrial & $\begin{array}{r}0.324 * * \\
(0.077)\end{array}$ & $\begin{array}{l}-0.111 \quad * * * \\
(0.041)\end{array}$ & $\begin{array}{r}0.214 \text { ** } \\
(0.089)\end{array}$ & $\begin{array}{r}-0.046 \\
(0.047)\end{array}$ & \\
\hline Export share: over $2 / 3$ & $\begin{array}{l}-0.458 * * \\
(0.116)\end{array}$ & $\begin{array}{r}-0.049 \\
(0.079)\end{array}$ & $\begin{array}{l}-0.488 \quad * * * \\
(0.127)\end{array}$ & $\begin{array}{l}-0.133 \\
(0.089)\end{array}$ & \\
\hline Export share: between $1 / 3$ and $2 / 3$ & $\begin{array}{r}-0.005 \\
(0.114)\end{array}$ & $\begin{array}{r}0.170 * * \\
(0.069)\end{array}$ & $\begin{array}{r}0.026 \\
(0.125)\end{array}$ & $\begin{array}{r}0.234 \\
(0.076)\end{array}$ & $* * *$ \\
\hline Found survey difficult & $\begin{array}{r}-0.006 \\
(0.125)\end{array}$ & $\begin{array}{r}0.130 * \\
(0.070)\end{array}$ & $\begin{array}{r}0.099 \\
(0.144)\end{array}$ & $\begin{array}{r}0.160 \\
(0.074)\end{array}$ & \\
\hline Multiple respondents involved & $\begin{array}{l}-1.829 * * \\
(0.622)\end{array}$ & $\begin{array}{r}0.861 \\
(0.398)\end{array}$ & $\begin{array}{l}-1.688 * * \\
(0.684)\end{array}$ & $\begin{array}{r}1.090 \\
(0.445)\end{array}$ & \\
\hline No outsourcing & $\begin{array}{r}-0.076 \\
(0.066)\end{array}$ & $\begin{array}{l}-0.097 \quad * * \\
(0.038)\end{array}$ & $\begin{array}{r}-0.068 \\
(0.073)\end{array}$ & $\begin{array}{r}0.206 \\
(0.084)\end{array}$ & $* *$ \\
\hline No knowledge of TTIP & $\begin{array}{l}-0.153 * * \\
(0.075)\end{array}$ & $\begin{array}{l}-0.010 * * \\
(0.044)\end{array}$ & $\begin{array}{l}-0.235 * * * \\
(0.080)\end{array}$ & $\begin{array}{l}-0.067 \\
(0.048)\end{array}$ & \\
\hline Share skilled & & & $\begin{array}{l}-0.852 \quad * * * \\
(0.269)\end{array}$ & $\begin{array}{r}0.642 \\
(0.152)\end{array}$ & \\
\hline $\mathrm{N}$ & 3,718 & 3,374 & 3,196 & 2,909 & \\
\hline Percent concordant & 68.7 & 59.2 & 69.6 & 59.1 & \\
\hline Percent discordant & 30.3 & 40.0 & 29.5 & 40.3 & \\
\hline Percent tied & 1.0 & 0.8 & 0.9 & 0.6 & \\
\hline
\end{tabular}

Levels of statistical significance of coefficients : *** 1\%** 5\%*10\% 
Table A5

Probability of answering the question on cybersecurity vis-à-vis probability of being attacked (logistic regressions)

\begin{tabular}{|c|c|c|c|c|c|c|c|c|}
\hline \multirow[b]{2}{*}{ Intercept } & \multicolumn{2}{|l|}{ Answered? } & \multicolumn{2}{|l|}{ Reported attack? } & \multicolumn{2}{|l|}{ Answered? } & \multicolumn{2}{|c|}{ Reported attack? } \\
\hline & $\begin{array}{r}2.206 \\
(0.225)\end{array}$ & $* * *$ & $\begin{array}{l}-1.390 * \\
(0.168)\end{array}$ & $* * *$ & $\begin{array}{r}3.123 \\
(0.301)\end{array}$ & $* * *$ & $\begin{array}{c}-1.352 \\
(0.177)\end{array}$ & $* * *$ \\
\hline Small & $\begin{array}{r}0.212 \\
(0.063)\end{array}$ & $* * *$ & $\begin{array}{c}-0.091 \quad * \\
(0.043)\end{array}$ & $* *$ & $\begin{array}{r}0.360 \\
(0.077)\end{array}$ & $* * *$ & $\begin{array}{r}-0.103 \\
(0.046)\end{array}$ & $* *$ \\
\hline South & $\begin{array}{r}0.228 \\
(0.096)\end{array}$ & $* *$ & $\begin{array}{l}-0.218 * \\
(0.054)\end{array}$ & $* * *$ & $\begin{array}{r}0.494 \\
(0.141)\end{array}$ & $* * *$ & $\begin{array}{r}-0.184 \\
(0.057)\end{array}$ & $* * *$ \\
\hline High-tech sector & $\begin{array}{r}-0.050 \\
(0.069)\end{array}$ & & $\begin{array}{r}-0.049 \\
(0.046)\end{array}$ & & $\begin{array}{r}-0.056 \\
(0.082)\end{array}$ & & $\begin{array}{r}-0.057 \\
(0.049)\end{array}$ & \\
\hline Industrial & $\begin{array}{r}0.208 \\
(0.074)\end{array}$ & $* * *$ & $\begin{array}{r}0.042 \\
(0.046)\end{array}$ & & $\begin{array}{r}0.263 \\
(0.093)\end{array}$ & $* * *$ & $\begin{array}{r}-0.007 \\
(0.049)\end{array}$ & \\
\hline Export share: over $2 / 3$ & $\begin{array}{r}-0.387 \\
(0.114)\end{array}$ & $* * *$ & $\begin{array}{r}-0.082 \\
(0.088)\end{array}$ & & $\begin{array}{r}-0.560 \\
(0.130)\end{array}$ & $* * *$ & $\begin{array}{r}-0.104 \\
(0.094)\end{array}$ & \\
\hline Export share: between $1 / 3$ and $2 / 3$ & $\begin{array}{r}-0.019 \\
(0.101)\end{array}$ & & $\begin{array}{r}0.154 * \\
(0.077)\end{array}$ & $* *$ & $\begin{array}{r}0.024 \\
(0.128)\end{array}$ & & $\begin{array}{r}0.153 \\
(0.080)\end{array}$ & $* *$ \\
\hline Found survey difficult & $\begin{array}{r}-0.369 \\
(0.091)\end{array}$ & $* * *$ & $\begin{array}{r}0.157 \text { * } \\
(0.072)\end{array}$ & $* *$ & $\begin{array}{r}0.091 \\
(0.151)\end{array}$ & & $\begin{array}{r}0.223 \\
(0.077)\end{array}$ & $* * *$ \\
\hline Multiple respondents involved & $\begin{array}{r}-1.559 \\
(0.600)\end{array}$ & $* * *$ & $\begin{array}{r}0.463 \\
(0.442)\end{array}$ & & $\begin{array}{r}-1.559 \\
(0.704)\end{array}$ & $* *$ & $\begin{array}{r}0.794 \\
(0.460)\end{array}$ & $*$ \\
\hline Foreign control & $\begin{array}{r}-0.241 \\
(0.097)\end{array}$ & $* *$ & $\begin{array}{c}-0.230 \quad * \\
(0.086)\end{array}$ & $* * *$ & $\begin{array}{r}-0.196 \\
(0.114)\end{array}$ & $*$ & $\begin{array}{r}-0.196 \\
(0.089)\end{array}$ & $* *$ \\
\hline Share skilled & $\begin{array}{r}-0.481 \\
(0.228)\end{array}$ & $* *$ & $\begin{array}{r}0.940 \\
(0.153)\end{array}$ & $* * *$ & $\begin{array}{l}-0.799 \\
(0.028)\end{array}$ & $* * *$ & $\begin{array}{r}0.821 \\
(0.160)\end{array}$ & $* * *$ \\
\hline No outsourcing & & & & & $\begin{array}{r}-0.030 \\
(0.076)\end{array}$ & & $\begin{array}{r}-0.087 \\
(0.044)\end{array}$ & $* *$ \\
\hline No knowledge of TTIP & & & & & $\begin{array}{r}-0.228 \\
(0.084)\end{array}$ & $* * *$ & $\begin{array}{r}-0.077 \\
(0.051)\end{array}$ & \\
\hline $\mathrm{N}$ & 3,409 & & 3,015 & & 2,999 & & 2,733 & \\
\hline Percent concordant & 67.7 & & 58.5 & & 70.5 & & 59.0 & \\
\hline Percent discordant & 31.4 & & 40.9 & & 28.7 & & 40.4 & \\
\hline Percent tied & 0.8 & & 0.6 & & 0.8 & & 0.6 & \\
\hline
\end{tabular}

Levels of statistical significance of coefficients : *** 1\%** 5\%*10\%

Table A6

Firms hit by at least one cyber attack: imputation diagnostics across data correction models

\begin{tabular}{l|c|c|c|c|c|c} 
& Base $(\mathrm{i})$ & Base (ii) & A(i) & A (ii) & B & C \\
\hline & & & & & & \\
Share of imputed data & 9.4 & 9.4 & 23.3 & 23.4 & 13.1 & 26.3 \\
N used to estimate imputation model & 3742 & 3225 & 2960 & 2540 & 2745 & 2145 \\
Model prediction: percent concordant & 57.5 & 58.2 & 57.8 & 58.3 & 59.1 & 59.2 \\
Model prediction: percent discordant & 41.3 & 41.1 & 41.1 & 41.0 & 40.3 & 40.2 \\
Model prediction: percent tied & 1.2 & 0.7 & 1.1 & 0.7 & 0.6 & 0.6
\end{tabular}


Firms hit by at least one cyber attack: complete-case analysis

\begin{tabular}{|c|c|c|}
\hline & \multicolumn{2}{|c|}{ Full sample } \\
\hline & $\%$ firms & $\%$ empl. \\
\hline \multicolumn{3}{|l|}{ Geographical area } \\
\hline North-West & 31.4 & 40.1 \\
\hline North-East & 36.3 & 43.6 \\
\hline Centre & 39.6 & 54.8 \\
\hline South and Islands & 25.8 & 29.7 \\
\hline \multicolumn{3}{|l|}{ Number of employees } \\
\hline $20-49$ & 31.6 & 31.7 \\
\hline $50-199$ & 35.1 & 36.8 \\
\hline $200-499$ & 44.7 & 43.4 \\
\hline 500 and over & 46.9 & 55.2 \\
\hline \multicolumn{3}{|l|}{$\begin{array}{l}\text { Tech / knowledge } \\
\text { intensity of sector }\end{array}$} \\
\hline High and medium-high & 34.7 & 47.9 \\
\hline Low and medium-low & 32.8 & 40.5 \\
\hline \multicolumn{3}{|l|}{$\begin{array}{l}\text { Exports as share of } \\
\text { turnover }\end{array}$} \\
\hline Less than $1 / 3$ & 32.0 & 42.5 \\
\hline Between $1 / 3$ and $2 / 3$ & 38.9 & 45.8 \\
\hline Over $2 / 3$ & 33.7 & 41.9 \\
\hline Total & 33.3 & 43.0 \\
\hline
\end{tabular}

Table A8

Firms hit by at least one cyber attack: base model

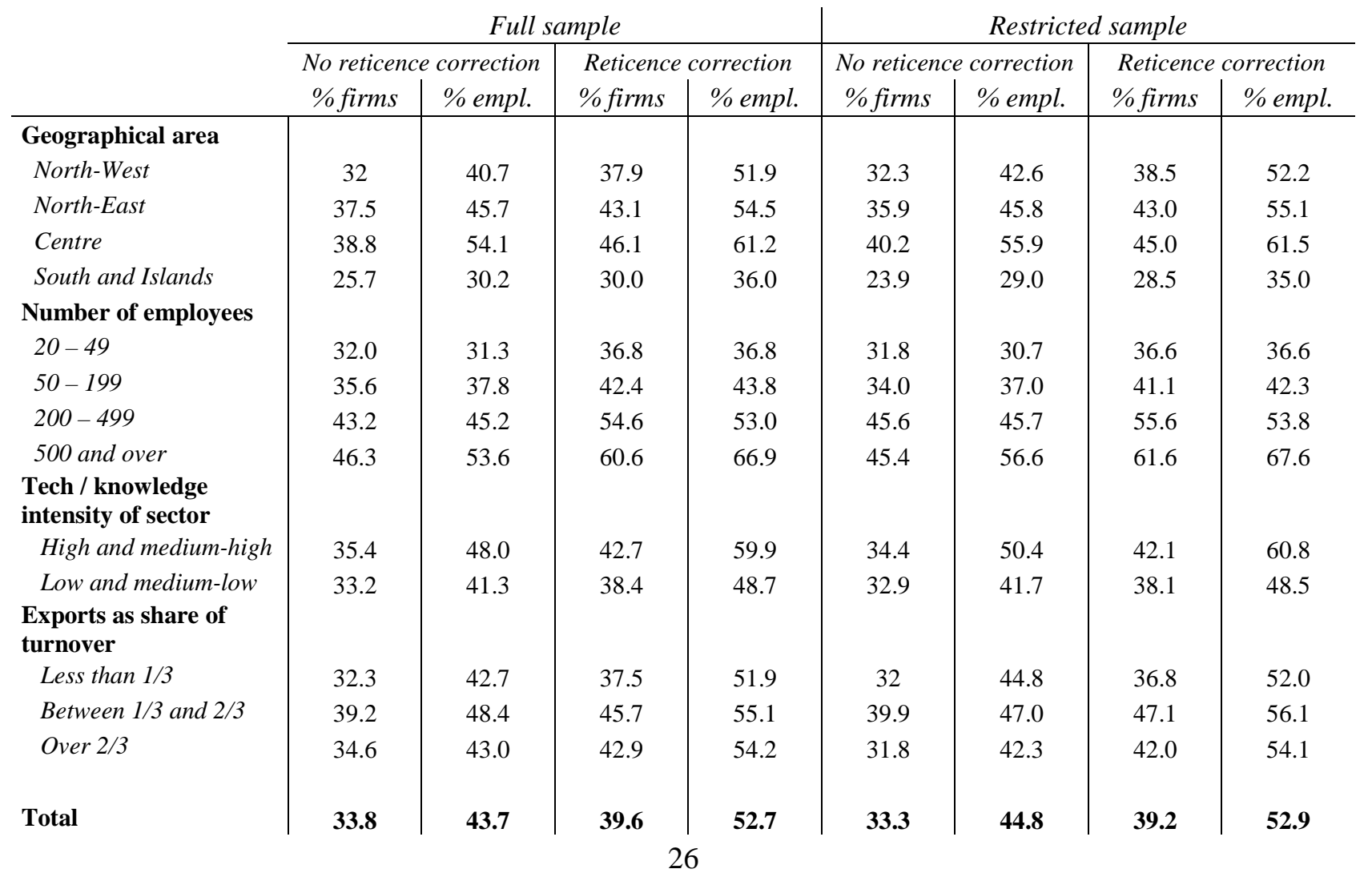


Firms hit by at least one cyber attack: data corrected for misdetection

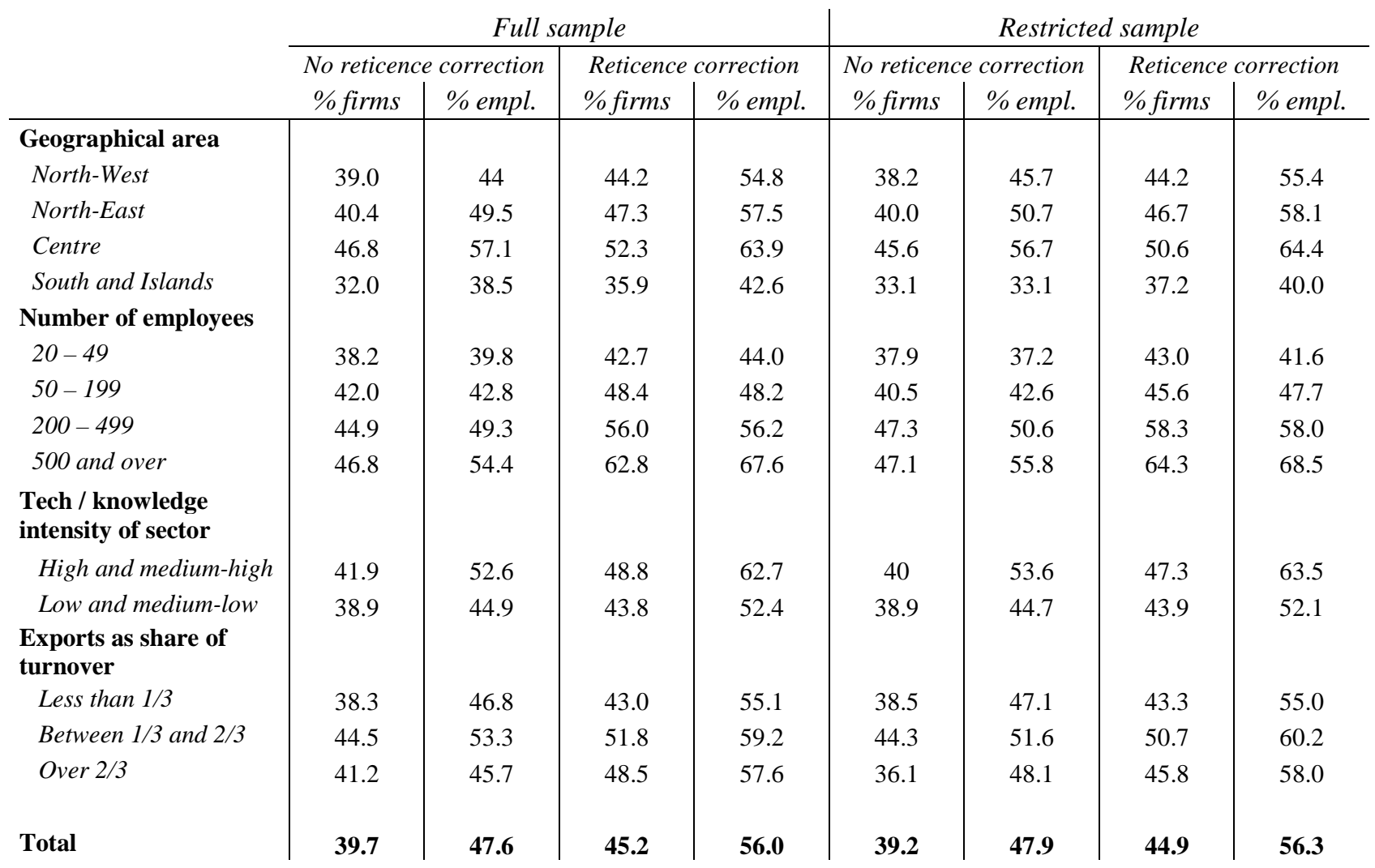

Firms hit by at least one cyber attack: data corrected for misreporting

\begin{tabular}{|c|c|c|c|c|}
\hline & \multicolumn{2}{|c|}{ No reticence correction } & \multicolumn{2}{|c|}{ Reticence correction } \\
\hline & $\%$ firms & $\%$ empl. & $\%$ firms & $\%$ empl. \\
\hline \multicolumn{5}{|l|}{ Geographical area } \\
\hline North-West & 34.0 & 47.5 & 40.5 & 57.1 \\
\hline North-East & 37.3 & 49.8 & 45.0 & 57.4 \\
\hline Centre & 40.7 & 59.7 & 46.4 & 64.9 \\
\hline South and Islands & 24.4 & 31.9 & 28.9 & 35.7 \\
\hline \multicolumn{5}{|l|}{ Number of employees } \\
\hline $20-49$ & 32.0 & 32.8 & 37.8 & 37.5 \\
\hline $50-199$ & 36.8 & 40.1 & 43.0 & 44.2 \\
\hline $200-499$ & 49.9 & 49.8 & 59.3 & 57.4 \\
\hline 500 and over & 50.3 & 62.6 & 65.7 & 73.2 \\
\hline \multicolumn{5}{|l|}{$\begin{array}{l}\text { Tech / knowledge } \\
\text { intensity of sector }\end{array}$} \\
\hline High and medium-high & 37.1 & 56.1 & 44.4 & 65.8 \\
\hline Low and medium-low & 33.5 & 45.0 & 39.4 & 51.0 \\
\hline \multicolumn{5}{|l|}{$\begin{array}{l}\text { Exports as share of } \\
\text { turnover }\end{array}$} \\
\hline Less than $1 / 3$ & 32.6 & 47.2 & 38.2 & 54.4 \\
\hline Between $1 / 3$ and $2 / 3$ & 41.3 & 54.2 & 49.2 & 60.9 \\
\hline Over $2 / 3$ & 36.0 & 52.5 & 44.3 & 61.1 \\
\hline Total & 34.5 & 49.0 & 40.8 & 56.4 \\
\hline \multicolumn{5}{|c|}{27} \\
\hline
\end{tabular}


Firms hit by at least one cyber attack: data corrected for misdetection, misreporting

\begin{tabular}{l|c|c|c|c}
\multicolumn{2}{c}{} & \multicolumn{2}{c|}{ No reticence correction } & \multicolumn{2}{c}{ Reticence correction } \\
\cline { 2 - 5 } & \% firms & \% empl. & \% firms & \% empl. \\
\hline Geographical area & & & & \\
North-West & 41.6 & 54.0 & 46.4 & 61.5 \\
North-East & 43.4 & 51.6 & 49.2 & 59.8 \\
Centre & 45.7 & 60.7 & 49.9 & 67.0 \\
South and Islands & 32.3 & 35.4 & 34.8 & 40.9 \\
Number of employees & & & & \\
20-49 & 38.9 & 39.4 & 42.6 & 43.7 \\
50-199 & 43.6 & 44.6 & 48.8 & 48.1 \\
200-499 & 55.4 & 58.6 & 63.4 & 65.0 \\
500 and over & 52.5 & 62.6 & 67.0 & 73.6 \\
Tech / knowledge & & & & \\
intensity of sector & & & & \\
High and medium-high & 45.5 & 59.9 & 51.0 & 69.1 \\
$\quad$ Low and medium-low & 39.6 & 48.7 & 43.8 & 54.6 \\
Exports as share of & & & & \\
turnover & & & & \\
Less than 1/3 & 39.3 & 50.9 & 43.1 & 58.1 \\
Between 1/3 and 2/3 & 51.4 & 59.5 & 55.9 & 64.0 \\
Over 2/3 & 38.7 & 54.2 & 47.1 & 64.1 \\
Total & & & & \\
& $\mathbf{4 1 . 2}$ & $\mathbf{5 2 . 7}$ & $\mathbf{4 5 . 8}$ & $\mathbf{5 9 . 9}$ \\
& & & &
\end{tabular}




\section{References}

Anderson, R. (1993), 'Why Cryptosystems Fail', Proceedings of the 1st Association for Computing Machinery on Computer and Communications Security.

Anderson, R. (2001), 'Why Information Security is Hard - an Economic Perspective', Proceedings of the $17^{\text {th }}$ Annual Computer Security Applications Conference.

Asghari, H., M. J. G. van Eeten and J. M. Bauer (2015), 'Economics of Fighting Botnets: Lessons from a Decade of Mitigation', IEEE Security \& Privacy 13(5).

Bank for International Settlements and Board of the International Organization of Securities Commissions (2016), ‘Guidance on Cyber Resilience for Financial Market Infrastructures'.

Banca d'Italia (various years), 'Survey of Industrial and Service Firms'.

Banca d'Italia (various years), ‘Business Outlook Survey of Industrial and Service Firms'.

Center for Strategic and International Studies (2016), 'Significant Cyber Incidents since 2006'.

Crown Commercial Service of the United Kingdom Government (2016), 'Procurement Policy Note Cyber Essentials Scheme'.

European Commission (2016), Commission Implementing Decision (EU) 2016/1250 pursuant to Directive 95/46/EC of the European Parliament and of the Council on the adequacy of the protection provided by the EU-U.S. Privacy Shield.

European Court of Justice (2015), Judgment of the Court C-362/14 (Maximilian Shrems vs Data Protection Commissioner).

Friedman, A. (2013), 'Cybersecurity and Trade: National Policies, Global and Local Consequences', Center for Technology Innovation at Brookings.

G7 Ise-Shima Leaders’ Declaration (2016).

KPMG (2015), 'Health Care and Cyber Security'.

Mandiant Consulting (2016), 'M-Trends Report'.

McAfee and Center for Strategic and International Studies (2016), 'Hacking the Skill Shortage: a Study of the International Shortage in Cybersecurity Skills'.

Moore, T. and R. Anderson (2011), 'Internet Security', in Peit, M. and J. Waldfogel (eds.), The Oxford Handbook of the Digital Economy, Oxford University Press.

Moore, T., S. Dynes and F.R. Chang (2016), 'Identifying How Firms Manage Cybersecurity Investment', mimeo. 
PriceWaterhouseCoopers (various years), ‘The Global State of Information Security Survey'.

Little, R. and D. Rubin (2002), Statistical Analysis with Missing Data, Wiley, Hoboken.

Spanos, G. and A. Lefteris (2016), 'The Impact of Information Security Events to the Stock Market: a Systematic Literature Review', Computers \& Security 58: 216-229.

United Kingdom Department for Culture, Media and Sport (2016), 'Cyber Security Breaches Survey: Main Report'.

United Nations General Assembly (various years), Reports of the Group of Governmental Experts on Developments in the Field of Information and Telecommunications in the Context of International Security.

United States Department of Defense, General Service Administration, National Aeronautics and Space Administration (2016), 'Federal Acquisition Regulation; Basic Safeguarding of Contractor Information Systems', Federal Register 81(94): 30439 - 30447.

van Eeten, M., J. M. Bauer, H. Ashgari, S. Tabatabaie and D. Rand (2010), 'The Role of Internet Service Providers in Botnet Mitigation: an Empirical Analysis Based on Spam Data', OECD Science, Technology and Industry Working Papers, 2010/05.

VMWare (2016), 'University Challenge: Cyber Attacks in Higher Education'

World Bank (2016), ‘World Development Report 2016: Digital Dividends'.

World Economic Forum (various years), 'Global Risk Report'.

World Economic Forum (2014), ‘Risk and Responsibility in a Hyperconnected World'. 